\title{
Social Cues of (Un)Trustworthy Team Members
}

\begin{abstract}
This study investigates the way in which and the extent to which students engage in social categorization during the process of self-selecting team members for a team assignment. The discovery-oriented method of grounded theory was used. Data were gathered from a sample of 38 undergraduate marketing students using the Zaltman Metaphor Elicitation Technique. Results indicate that, when faced with having too little information about classmates, students use a variety of social cues to cognitively categorize classmates, and then make a series of inferences about their personality, values, and trustworthiness based on the category in which they are placed. In addition, students use the inferences to help make decisions about who to approach and who to avoid during the self-selection process. Making inferences about classmates based on the social category in which they are placed, rather than on individual merit, is stereotyping. Behaving differently toward classmates based on the social category in which they are placed is discrimination. All 38 student subjects who participated in this study reported that they have used social cues to help decide who to approach and who to avoid during team formation, and 13 reported doing so every time they have self-selected team members.
\end{abstract}




\section{Introduction}

Published academic literature on team assignments concentrates on their intended consequences in the form of benefits that accrue to students (e.g., Hansen, 2006; Williams, Beard, \& Rymer, 1991), problems or unintended consequences that detract from the value of team assignments (e.g., Batra, Walvoord, \& Krishnan, 1997; McCorkle et al., 1999; Neu, 2012), and guidance for how to design different aspects of team assignments to enhance their effectiveness (e.g., Deeter-Schmelz, Kennedy, \& Ramsey, 2002; Dommeyer, 2007; Wood, 2003). One key aspect for which published literature provides guidance is the approach by which teams are formed. Those who have provided guidance, however, disagree on the fundamental issue of whether instructors or students should have decision-making authority for team formation.

While instructors, when they do make decisions, can randomly assign students to teams, some authors explain that instructors should assign students to achieve a desired mix of resources and level of diversity within each team, and to achieve equity in resources across teams (e.g., Blowers, 2003; Muller, 1989; Bacon, Stewart, \& Stewart-Belle, 1998). Other authors recommend giving complete decision-making authority to students. Arguments for doing so are that "[s]tudents are best placed to engineer their teams (Huxham \& Land, 2000) since they may have greater insight into the characteristics of potential team members than teaching staff' (Seethamraju \& Borman, 2009, p. 38), and “self-selected groups do add more value to students' experiences with group work" (Chapman, Meuter, Toy, \& Wright, 2006, p. 568). Instead of either instructors or students having complete decision making authority, some authors propose an approach through which decision-making is shared (Matta, Luce, \& Ciavarro, 2010). 
But when students are asked to make decisions during team formation, how do they actually decide who to include in, and exclude from, their team? Does the decision making process result in intended consequences or benefits for students, or does the process lead to unintended consequences that detract from the value of the team assignment experience for at least some students? Published research addresses students' decision making when they have prior knowledge about their classmates (Connerley \& Mail, 2001; Neu, 2012; Seethamraju \& Borman, 2009). Very limited published research, however, addresses students' decision making during team formation when they do not have prior knowledge of each other.

A recent study provides preliminary evidence that, in the absence of prior knowledge about classmates, some students use social cues — behaviors and traits - to cognitively categorize their classmates and make inferences about them based on the category in which they are placed (Neu, 2012). Interferences are then used to make decisions about who to approach and who to avoid during team formation. In other words, the study revealed that some students engage in stereotyping, the process of using social cues to cognitively categorize others and making inferences about them based on the category in which they are placed (Schneider, 2004). The study also suggested that some students engage in discrimination, the process of behaving differently towards people based on the social category in which they are placed (Schneider, 2004).

The preliminary insights from Neu (2012) provided the impetus for this study, the overarching purpose of which is to clarify the process through which students make decisions during the team formation process when they have no prior knowledge of their classmates. Specifically, the study set out to 1) further investigate the extent to which undergraduate business students engage in social categorization while selecting team members, 2) identify the social 
cues that students tend to use if they do engage in social categorization, and 3) clarify how social cues are used to make decisions and guide behavior during team formation. In so doing, the study advances understanding of unintended consequences of team assignments and provides guidance on whether instructors or students should make decisions about who works with whom.

The remainder of this article is organized as follows. First, background literature that motivated the study and guided the inductive research process is discussed. Then, research methodology is explained which is followed by results. The article concludes by discussing implications and limitations of the study.

\section{Background Literature}

\section{Team Formation}

Published academic literature offers three perspectives on how to organize students for team assignments. A key difference among the perspectives is in who should have decision making authority during team formation. First, some authors have concluded that instructors should decide who will work with whom because doing so leads to more positive team assignment experiences for students (Feichtner \& Davis, 1985). When instructors do assume responsibility for team formation they commonly assign students randomly. Random assignment is easy to administer and intended to accomplish the same effects as randomizing subjects in an experiment (Bacon, Stewart, \& Anderson, 2001). Specifically, students are randomly assigned to produce adequate heterogeneity within teams and equity in resources among teams. In practice, however, random assignment can result in something quite different from that which was intended. That is, teams can differ in the extent to which they possess the needed mix of project relevant resources or they can differ in their collective academic abilities. These random differences mean that some students can receive a lower or higher grade on the assignment 
simply due to chance (Bacon et al., 1998). Random assignment can also yield teams that have too little demographic diversity (Bacon et al., 1998) which then limits the opportunity for students to develop their diversity skills. Research has also reported that random assignment increases the likelihood that students will have an overall negative experience (Feichtner \& Davis, 1985).

To avoid the shortcomings of random assignment, instructors should organize students to achieve a desired mix of project relevant resources and level of diversity within teams, and an equitable allocation of resources across teams. Specifically, an instructor can first segment students on their skills or strengths (Blowers, 2003; Muller 1989; Scott, Bisland, Tichenor, \& Cross, 1994), work experience (Beheshtian-Ardekani \& Hahmood, 1998), academic achievement (Scott, Bisland, Tichenor, \& Cross, 1994), or major (Gosenpud, 1989). Then, instructors can assign students to ensure that each team has the needed mix of resources, and that all teams are on a level playing field with respect to their collection of resources. Also, instructors can segment and assign students based on demographic attributes to achieve a desired level of intrateam diversity (Bacon et al., 1998).

The second perspective on team formation is that students should be given complete decision-making authority and self-select their team members. Self-selection leads to early team cohesiveness (Mello, 1993) and, when compared to random assignment, higher student ratings on a number of team dynamic, attitude, and outcome measures (Chapman et al., 2006). Also, self-selection has been shown to lead to higher student satisfaction with overall team performance than when the instructor makes decisions (Connerley \& Mael, 2001).

When students do make decisions during team formation they appear to emphasize a broad range of selection criteria (Connerley \& Mail, 2001) that organize along three dimensions 
that Seethamraju and Borman (2009) labeled skills/knowledge, task management, convenience, and social cohesion. Seethamraju and Borman (2009) also found that a team's grade is positively related to the extent to which students make decisions using the criteria. Also, a study by Neu (2012) found that students tend to form a team assignment social network in which network members are tied by beliefs about each other's trustworthiness. Then, to the extent possible, when students make decisions during team formation they team up with trustworthy members of their network.

While self-selection has been linked to some positive outcomes for students, the method can lead to what Bacon et al. (2001) refer to as the "remainder" problem in which one or a few students are left without a team after the self-selection process. In addition, self-selected teams can lack the needed mix of resources or desired level of diversity (Jalajas \& Sutton, 1984-1985), which can be addressed by asking students to self-select teams in a constrained way. For example, to create the desired mix of resources within teams, students can identify the critical roles that different members of a work team may need to perform for any team to be successful, self-identify the roles that align with their strengths, and then form teams such that as many critical roles as possible are represented in the team (Potosky \& Duck, 2007). To increase withinteam diversity, students can be asked to self-select teams such that each team meets a quota of members who fit one or more attributes (Bacon et al., 2001).

Finally, some authors propose an approach in which students and instructors share decision making authority about who works with whom. The basic approach is one in which students first indicate their preferred team member(s) to the instructor, and the instructor then makes the final decisions. For example, students can first identify a friend, and then the instructor can randomly assign pairs of friends to teams (Mahenthiran \& Rouse, 2000). Or, 
students can first list with whom they do and do not want to work, and then the instructor can

form teams while trying to accommodate students’ preferences (Matta et al., 2010).

\section{Social Categorization and its Consequences}

Social categorization is a fundamental cognitive process through which one uses social cues — behaviors and traits - to segment people and organize information about them (Schneider, 2004). There are two perspectives on the nature of the problem that motivates social categorization. Some argue that people have limited cognitive resources to deal with a highly complex social environment, an environment in which there are too many social stimuli and too much heterogeneity among them. Categorizing people is seen as a way to simplify the complex social environment (e.g., Taylor, 1981). Others argue that, rather than too much information, the basic cognitive problem that people face is too little information, and creating categories helps people make inferences about the attributes of others. These inferences fill in the blanks and help people cope with not having information that is directly provided by their senses (e.g., Medin, 1988). Regardless of the perspective one takes on the underlying problem, when people are placed in a category they are inferred to have something in common with others in the category and inferred to be different from people in other categories (Schneider, 2004). And, the cognitive process of making inferences about people based on the category in which they are placed, rather on individual merit, is stereotyping (Schneider, 2004)

While stereotyping is a cognitive process that leads to making inferences about the similarities and differences among people, the inferences are linked to affective and behavioral responses (Stephan \& Stephan, 1993). Affective responses towards a social category of people or individuals from that category is prejudice (Schneider, 2004). Prejudice is normally associated with negative affective responses, but one's prejudice can be positive. Behavioral responses 
toward a category of people or individuals from the category is discrimination (Schneider, 2004). Discriminatory behaviors range from blatant acts towards others to subtle acts that may not even be consciously articulated by the person engaging in the act or perceived by the person who is the target of the act (Crosby, Bromley, \& Saxe, 1980). Discriminatory behaviors also range from those that are idiosyncratic and carried out by individuals to those that that are driven by institutional policies and norms (Schneider, 2004).

\section{Implications for Team Formation}

Students will, at times, have to cope with the problem of too little information during the team formation process. That is, students will have to make decisions about with whom to form a team in the absence of prior knowledge about their classmates. Students can deal with the problem by simply turning to others in close proximity, and some likely do. But students tend to view such behavior as too risky and prefer to apply selection criteria (Connerley \& Mail, 2001; Seethamraju \& Borman, 2009) and find the "right" or trustworthy team members (Neu, 2012). Students will likely try to cope with their lack of knowledge by using readily available information in the form of social cues to cognitively categorize classmates and then respond based on the category in which they are placed. It was against this backdrop that this study set out to investigate the way in which and the extent to which students use and respond to social cues during the team formation process.

\section{Methodology}

The discovery-oriented method of grounded theory was used (Strauss \& Corbin, 1998) since it provided an appropriate way to pursue a topic that has received little attention in published academic research. Initially, undergraduate marketing and management students were recruited from two sections of an upper division Marketing Research class taught during one 
semester at a university in the Southwestern United States. The university has a total of 11,300 students of which $61 \%$ are female. The student body composition includes 37 percent Caucasian, 30 percent Latino/a, 9 percent Asian and Pacific Islander, and 3 percent African American. Eighty-three percent of undergraduate students are from 17 to 25 years old, and their median age is 21 .

Extra credit was offered as an incentive to participate in the study. All students in the two sections were also offered an alternative extra credit exercise if they desired extra credit, but preferred not to participate in the study. In total, 38 students - 13 women and 25 men- did participate and all subjects were within one semester of graduating with a Bachelor of Science Degree in Business Administration. Subjects reported that, on average, 90\% of their business classes included at least one team graded assignment and that $76 \%$ of their teams were selfselected. As such, the sample was homogeneous (Patton, 2002) in that all subjects had experienced several similar team graded assignments for which they self-selected team members.

Data were collected using the Zaltman Metaphor Elicitation Technique (ZMET) (Zaltman \& Coulter, 1995). ZMET is founded on the premise that thoughts occur as images, and only infrequently verbal images. As such, the technique provides a way for research subjects to represent their thoughts in a nonverbal way. By doing so, a researcher gets closer to the way in which thoughts naturally occur and increases the ability to learn about them. ZMET also involves a form of personal interview during which subjects verbally communicate about their collection of images. Combining the nonverbal images with verbal language then deepens understanding of subjects' mental models that drive their thinking and behavior.

For this study, the process began by asking each subject to assume that he or she is starting a new business class and asked to self-select members for a team assignment. In 
addition, subjects were told to assume that they have no prior knowledge of any of their classmates; they are in a classroom full of strangers. Subjects were then given about two weeks to accumulate images that visually represent classmates they would tend to approach and ask to be part of a team, and accumulate images that visually represent classmates they would tend to avoid and not ask to be part of a team. Subjects were told that magazines provide a good source of images and that images from any other source would be fine (see Figure A.1 and Figure A.2 in the Appendix for example images from one subject).

After accumulating his or her images - all of which came from magazines and the Internet — each subject participated in a guided conversation (Zaltman \& Coulter, 1995). All guided conversations were conducted by the same researcher and lasted from 60 to 90 minutes. Each conversation began by asking for the subject's class standing, an estimate of the percentage of the subject's business classes that included at least one team graded assignment, and an estimate of the percentage of their team assignments for which they self-selected team members. During the main part of the conversation, each subject was guided to talk about four topics for each image. First, subjects were asked to explain the aspects of the image that led him or her to place the image in the approach or avoid category. Second, the conversation focused on understanding the associations the subject made to specific aspects of the image. Third, the conversation focused on understanding what the subject would anticipate if the person represented in the image became a team member for a graded assignment. And fourth, the conversation led to a discussion about feelings the subject associated with the image and the person reflected in it. This part of the conversation also included a question about how the subject would feel if he or she ended up on a team with the person represented in the image.

The conversation first covered one category of images - either approach or avoid — and 
then focused on the other category. After speaking about a category of images, the subject was asked to think back on all of his or her team assignments while in the College of Business and roughly estimate how frequently he or she used the cues represented in the images to help decide who to approach or avoid during team formation. Subjects were asked to respond using a fivepoint scale: never, about one-quarter of the team assignments, about one-half of the team assignments, about three-fourths of the team assignments, and every team assignment. Each conversation was audio recorded and transcribed. In total, subjects explained 438 images, of which 224 represented classmates they would approach and 214 represented those they would avoid.

Data analysis was an ongoing process of microanalysis and followed procedures outlined by Strauss and Corbin (1998). Specifically, each interview transcription was analyzed in a Microsoft Word file to identify relevant and meaningful units of text—words, phrases, sentences, or paragraphs. Text units were organized into groups to isolate the main ideas in the data, and each group was given a label. The individually labeled groups of data were further organized into logical groups that were also each given a label. This coding was first performed for an individual subject and the results were subsequently integrated with those of other subjects. Through this process a set of concepts was identified from the labeled groups of data and, as the data structure emerged, extant literature was reviewed for names for specific concepts and their dimensions (Strauss \& Corbin, 1998). Memos were routinely written to record analytic thoughts, and diagrams were developed and revised to depict relationships among concepts (Strauss \& Corbin, 1998).

Theoretical saturation (Glaser \& Strauss, 1967) was reached with 20 subjects, in that the concepts were well-developed and no new relevant data were emerging. Eighteen additional 
subjects were then used to confirm and add credibility to the findings that emerged from the first 20 subjects (Patton, 2002). The complete list of concepts and the number of participants who mentioned them are provided in the Tables A.1 and A.2 (see the Appendix).

Data analysis also included axial coding (Straus \& Corbin, 1998) to identify paired concept relationships (Zaltman \& Coulter, 1995) between social cues and the inferences subjects made about them. The relationships were elicited during the guided conversation as subjects explained the associations they made to specific aspects of an image. Concept pairs are embedded in reasoning chains (Zaltman \& Coulter, 1995) as illustrated in Figure A.1 and Figure A.2. For example, Figure A.2 includes the following reasoning chain comprised of a number of paired concept relationships: too much make-up (social cue) $\rightarrow$ value bettering self and fashion (wrong values); unprofessional, not serious, not confident (negative personality traits) $\rightarrow$ low quality work, late work (untrustworthy team member) $\rightarrow$ confrontation, fight about priorities, stress (negative emotional consequences). Data collection was, in large part, a process of eliciting from each subject their reasoning chains for social cues, and data analysis included isolating and manually counting the number of times construct pairs were mentioned across the 38 subjects.

Results were then summarized in a consensus map (Zaltman \& Coulter, 1995) to visually illustrate concepts and relationships among them (Figure 2 in Results). Since the map is intended to represent "most of the thinking of most [students] most of the time" (Zaltman \& Coulter, 1995 p.44), the map includes concepts that were mentioned by at least 12 of the 38 participants (about one-third) which is consistent with Zaltman and Coulter (1995). The main construct pairs that link social cues to inferences about personality and values appear in Table A.2 (see the Appendix). Consistent with Zaltman and Coulter (1995), the table emphasizes construct pairs 
that were mentioned by at least nine participants (about one-quarter). The table also highlights construct pairs that were mentioned by six, seven, or eight participants to emphasize those that were close to the suggested one-quarter guideline.

\section{Results}

The main conclusion from this study is that the process of self-selecting team members is, in part, a process of socially categorizing classmates and behaving differently towards them based on the category in which they are placed. As shown in Figure 1, 27 of 37 subjects estimated that for at least one-half of their self-selected project teams they used social cues to decide who to approach, and 32 subjects estimated that they used social cues at least one-half of the time to decide who to avoid. Very notably, all subjects reported having used social cues to some extent while self-selecting team members.

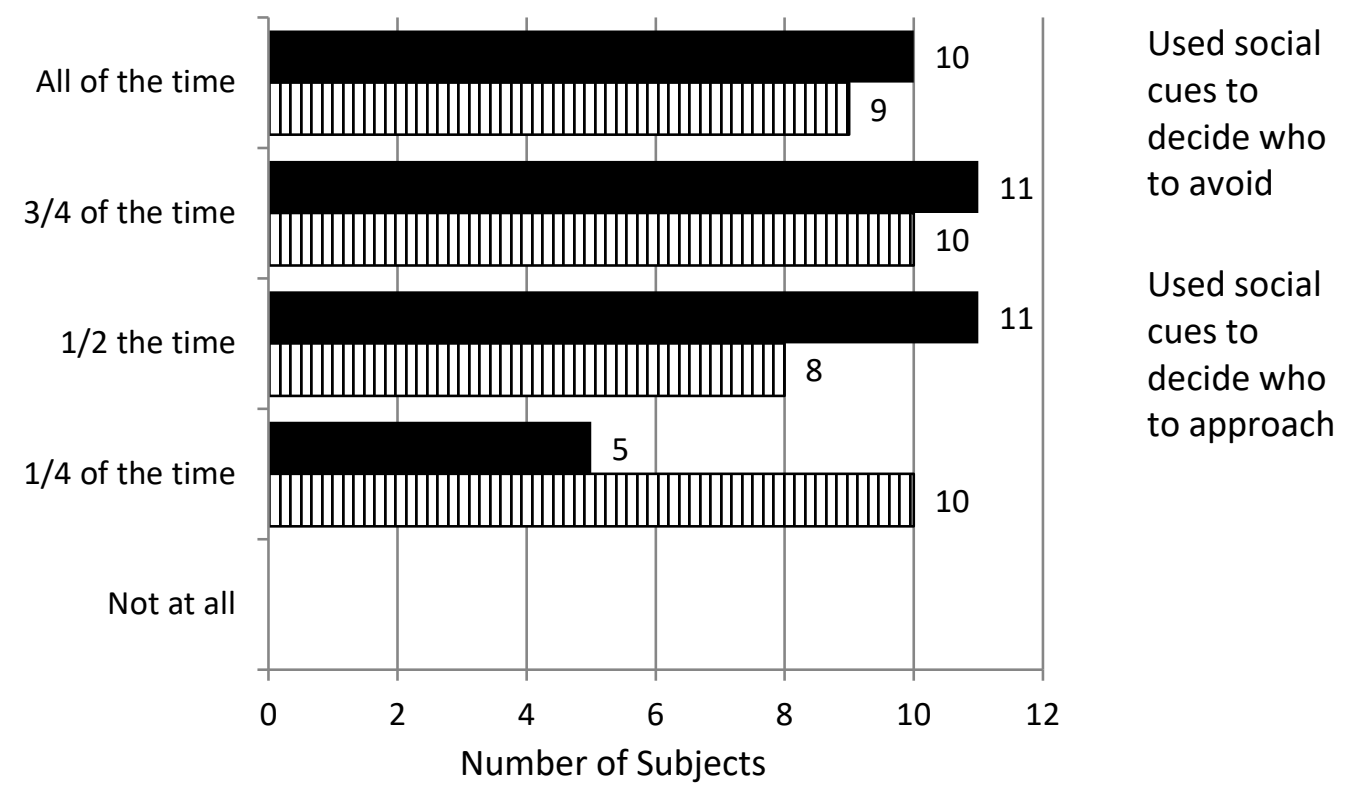

Figure 1. Extent to Which Social Cues Were Used 
When students do not have prior knowledge about classmates, their behavior during the self-selection process is in part guided by a series of inferences shown in Figure 2. That is, social cues are cognitively associated with beliefs about others' personality and values that are, in turn, linked to beliefs about trustworthiness. Beliefs about others' trustworthiness then give rise to inferences about goals, and inferences about goals are linked to behavior. The following sections first explain inferences students make about goals, and then inferences about others' trustworthiness, personality, and values. The "Results" section concludes with an explanation of social cues about which inferences are made.

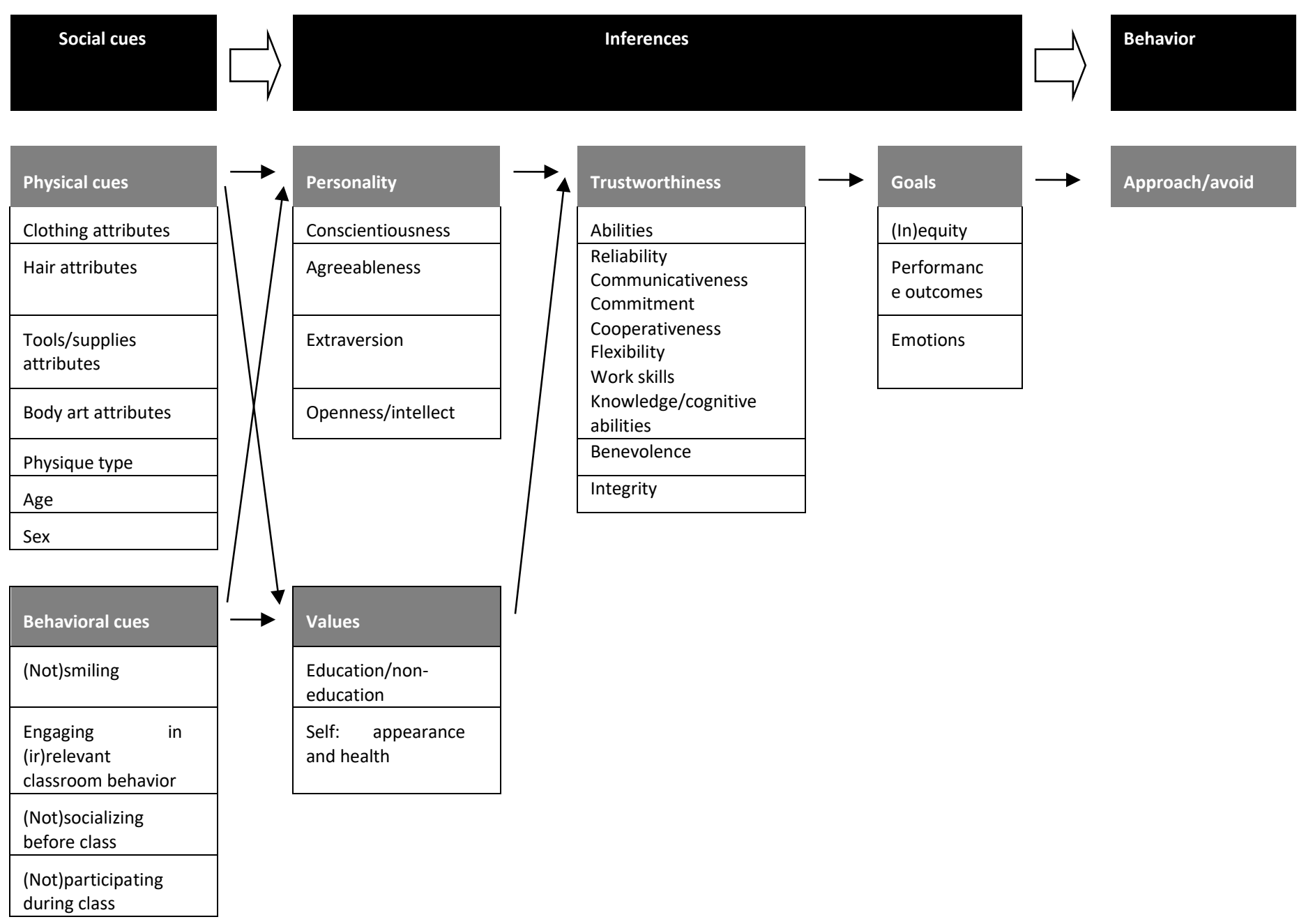

Figure 2. Consensus Map 


\section{Inferences About Goals}

Results indicate that students engage in social categorization to help achieve three fundamental goals. First, (in)equity appeared in a least one reasoning chain for all 38 subjects and it appeared multiple times for most. (In)equity deals with the extent to which the contributions of individual team members meet others' expectations in quantity and quality (Neu, 2012). Basically, social categorization is a cognitive process employed to increase the chance that eventual team members will contribute in an equitable way, and reduce the chance of having to "pick up the slack" or take on additional work to deal with inequity when it does occur. Second, performance evaluation was mentioned by 25 participants and for those who did, images in the avoid category were linked to a negative "hit" to one's grade, and images in the approach category were linked to a positive impact on one's grade. As such, students engage in social categorization to improve their chance of achieving the grade to which they aspire and, when combined with (in)equity, contributing their fair share in doing so. For example, following is a reasoning chain from one subject who spoke about an image of a student in his avoid category: not participating, don't raise hand in class (behavioral cue — not participating during class) $\rightarrow$ super shy (low in extroversion) $\rightarrow$ makes presentation better if people are confident in delivery (abilities) $\rightarrow$ if [the person in the image] is a team member will give him the smallest part of presentation, the easier part, might detract from presentation (inequity), and your grade (negative performance outcome) $\rightarrow$ disappointed (negative emotion). Third, students engage in social categorization to decrease the chance of future negative emotional consequences and increase the chance of future positive emotions (see Table A.1 for specific emotions). One to seven different negative emotions appeared in the reasoning chains of 35 subjects, and the most frequently mentioned were anxiety/uncertainty, anger, sadness/unhappiness, and stress. On the other hand, 24 subjects 
mentioned from one to five positive emotions and the most frequently mentioned were confidence and relief.

\section{Inferences About Trustworthiness}

Whether a classmate is thought to be one who will facilitate or hinder the aforementioned goals depends on the extent to which they are inferred to be a trustworthy team member. Consistent with Mayer et al. (1995), trustworthiness is defined as one's beliefs about another's ability, benevolence, and integrity. As shown in Table A.1, the ability dimension of trustworthiness was mentioned far more frequently than benevolence and integrity.

Ability. All 38 subjects used beliefs about others' ability to separate those they would approach from those they would avoid. In doing so, subjects emphasized five traits commonly used to describe one's ability to be an effective member of a work team: reliability, communicativeness, commitment, cooperativeness, and flexibility (e.g., Driscell et al., 2006; Loughry et al., 2007). Without exception, images in the approach category were associated with the positive form of these traits and images in the avoid category were associated with the negative form.

Reliability is the most prevalent teamwork-related inference students make about their classmates (explained by 36 subjects). Classmates in the approach category are believed to be the type of team member who can be relied on to meet expectations in both the quantity and quality of their contributions. In other words, they can be relied on to contribute to the team project in an equitable way. On the other hand, those in the avoid category are inferred to be unreliable team members who will not do their fair share and/or not do it well. Beliefs about reliability also deal with whether others can be relied on to complete their work on time and, to a lesser extent, whether they can be relied on to attend meetings and arrive on time. 
Communicativeness was the second most prevalent teamwork-related attribute ( 28 subjects). The dominant issue is the extent to which others are believed to be team members who will openly share ideas and opinions. To a lesser extent, communication also deals with accessibility when needed and responsiveness to communication.

Commitment deals primarily with the extent to which one cares about the project and the team's performance (24 subjects). While care and caring, or lack thereof, were used very frequently to describe individuals in the approach and avoid categories, commitment was also described using terms such as placing high value on, giving priority to, investing in, focusing on, and being dedicated to, a team project.

Students also form beliefs about their classmates' cooperativeness, or the extent to which they work effectively with others. That is, individuals represented by images in the approach category were characterized as "non-argumentative," "cooperative," "good team players" who are "easy to work with," "willing to take on tasks," and "easy to bond with." On the other hand, individuals represented by images in the avoid category were described as "uncooperative," "individualized," "stubborn" types who are "hard to work with" and will "create conflict" and "poor team cohesiveness."

Flexibility is the fifth main belief about team skills and was mentioned less frequently (12 subjects) than the other four attributes. Beliefs about flexibility deal primarily with two things: the extent to others are thought to be open and willing to consider the ideas of others, and the extent to which one is flexible with their time.

In addition to attributes of an effective team member, beliefs about work skills were prevalent (19 subjects) when characterizing classmates to approach and classmates to avoid. In general, subjects explained how those in their approach category were thought to be strong in project 
relevant skills including organization, time management, oral communication, written communication, technology, research, and English. Those in the avoid category were then believed to be deficient in one or some combination of these skills.

The final category of ability deals with inferences about knowledge and cognitive ability which were highlighted by 18 subjects. For some, those to be approached are thought to possess knowledge gained from their "real-world" experience or understanding of course content that will be beneficial to a project. In addition, individuals in the approach category are inferred to be able to contribute knowledge or ideas that are different from those of other team members. Those who can "think different" are the individuals who can contribute "really good input," "great ideas," or "new thinking" that will make the team's deliverable stand out and ultimately boost the team's grade.

Integrity. Beliefs about others' integrity, or the extent to which one's values are deemed acceptable (Mayer et al., 1995), are also influential when categorizing others as those to approach or avoid. Integrity arose when subjects mentioned inferences about others' specific values, and seven subjects explained the acceptability or appropriateness of those values. For example, individuals in the approach category were described as "having their priorities in line" or having "shared values," while those to be avoided have "priorities that are out of whack" or they simply have values that are "wrong."

Benevolence. Benevolence, or having others' best interests in mind (Mayer et al., 1995), received the least attention among the three dimensions of trustworthiness. Benevolence emerged as subjects explained personality characteristics (e.g., helpfulness is a specific trait in the agreeableness dimension), and as they explained what they would anticipate if others were a team member. The basic issue is that classmates who are believed to "think about my needs as 
well as hers," or "think about the team and not just herself," are placed in the approach category and those who "will not take the time to help others" are not.

\section{Inferences About Personality and Values}

Personality. As subjects talked about why they placed images in either the approach or avoid category they often explained, before anything else, specific personality traits. As shown in Table A.1, 25 different traits emerged that are consistent with those found in four of the "Big Five" personality dimensions: conscientiousness, agreeableness, extroversion, and openness or intellect (e.g., John \& Srivastava, 1999).

Conscientiousness was the most prominent dimension as 35 of 38 subjects mentioned specific traits such as hardworking, organized, focused/dedicated, reliable, and timely. The agreeableness dimension arose as subjects explained how they believed others to be welcoming, cooperative, easy-going, and helpful (mentioned by 31 subjects). The extroversion dimension emerged as subjects described others as outgoing, friendly, confident, and positive (28 subjects). And openness or intellect, which consists of specific personality traits such as intelligent, openminded, and creative, was mentioned by 28 participants.

Results indicate that inferences about all four personality dimensions are associated with the ability dimension of trustworthiness. The associations appear to be quite strong since all 38 subjects had one or more reasoning chains that link personality to attributes of ability. For example, subjects who mentioned specific traits of conscientiousness also mentioned team skills such as reliability and commitment, and work skills such as organization and time management. Those who mentioned specific traits of agreeableness also made reference to team skills such as cooperativeness and flexibility. Subjects who mentioned extroversion focused heavily on 
communicativeness or the willingness and ability to share ideas with other team members. And, subjects who mentioned openness or intellect mentioned attributes such as knowledge due to experience or different ideas deemed helpful for a team project.

In addition, there is likely a close link between personality and the benevolence dimension of trustworthiness, but the link was not nearly as prominent as that between personality and ability. The basic issue is that subjects who mentioned agreeableness traits such helpful and unselfish also described a team member who would have others' best interests in mind. For example, a reasoning chain from one subject consisted of the following: smiling (behavioral cue) $\rightarrow$ one who will think about me, think about my needs as well as hers (agreeableness) $\rightarrow$ think about the team, not just herself (benevolent team member) $\rightarrow$ relief, confidence (positive emotions).

Values. Students also make inferences about the extent to which their classmates place value on either education or non-educational aspects of life, and the extent to which classmates place value on self (appearance and/or health). Inferences about values are associated with beliefs about the ability dimension of trustworthiness. The basic link is that if a classmate is inferred to care about education and/or self, he or she is also inferred to care about a team project and thus will be a committed and reliable team member. As an example, one subject explained the following reasoning chain that included value on education: using a day planner (social cue) $\rightarrow$ organized (conscientious), serious about school/learning (value on education) $\rightarrow$ will be on time with tasks (reliability) $\rightarrow$ do fare share (equity), will not have to babysit (not more work for me) $\rightarrow$ relief, less stress (positive emotions). And, another subject's reasoning chain illustrates the association between value on appearance and ability: wearing baggy clothes, bad hygiene (social cues) $\rightarrow$ unacceptable appearance, not caring for self (value) $\rightarrow$ so they aren't going to care about the project (uncommitted), will not mesh with others, individualized 
(uncooperative) $\rightarrow$ not contribute to the project (inequity) $\rightarrow$ scared, annoyed (negative emotions). While placing too little value on one's appearance or health was commonly mentioned, some subjects mentioned just the opposite. The basic issue is that if others are inferred to place too much value on their appearance and/or health they are also inferred to commit too much of their time and energy to things like working out, and commit too little time and energy to a team project.

While several subjects frequently mentioned specific values, only seven subjects explained integrity. For those who did, integrity was in reference to either or both education and self. For example, one subject explained that others who place high value on education have their priorities in the "right place," and another subject stated that a woman who wears too much make-up places too much emphasis on herself and fashion and simply has the "wrong priorities."

\section{Social Cues}

As previously explained, when faced with the problem of too little information, undergraduate business students tend to use social cues to cognitively categorize their classmates. In total, subjects mentioned 19 different social cues (listed in Table A.2). This section first explains the physical cues and then the behavioral cues that appear in the consensus map (Figure 2); the cues are explained in order from the most to the least frequently mentioned. This section also explains inferences about personality and values that arise from the commonly used social cues (detailed in Table A.2).

Clothing attributes. Clothes are the most frequently mentioned physical cue to categorize classmates. Thirty-five subjects mentioned attributes of clothes and they did so in 137 of 438 images. Classmates to be approached wear what will be referred to as B-school casual clothes, which are moderate in style, conservative, coordinated, clean, ironed, and good-fitting. 
Images of B-school casual were described as appearing "put together," "well-kept," and "welldressed" which is, as one subject explained, the way "you should dress in business school." Those who are "put together" simply look like they are going to business school and not, as subjects explained, like they are going to a nightclub or a party, or like they just "rolled out of bed" or "came from the beach."

B-school casual clothes appear to be associated with positive beliefs about all four of the "big four" personality dimensions (Table A.2). Specifically, clothes that are moderate in style, conservative, coordinated, clean, ironed, and good-fitting are associated with conscientiousness - the person is hardworking, organized, and professional; agreeableness - the person is cooperative and welcoming; extroversion - the person is friendly; and openness/intellect - the individual is believed to be smart. Clothes are also associated with values. One who is dressed in B-school casual is thought to place high value on education since "they dress like they are going to business school," and high value on self or that he or she cares about appearance.

On the other hand, those who wear clothes that deviate too far from B-school casual tend to be placed in the avoid category. Their clothes are considered too stylish, fashionable, or flashy; too sexy or tight (for women); too revealing (men and women); too baggy or loose (for men); too wrinkled, too dirty, too old or "beat up"; or just too un-business school like (e.g., pajamas, sweatpants, or tank tops for men). Individuals placed in the avoid category due to their clothes were labeled as "thuggish," "gangster looking," "hipster," "street-oriented," or just downright "poorly dressed" which, as one subject stated, is "not the way you should dress in business." The key is that when a classmate's clothes deviate too far from B-school casual, he or she tends to be 
associated with negative traits in all four of the aforementioned personality dimensions and with placing too little value on education or self (appearance).

Hair attributes and facial hair attributes for men. Hair was the second most commonly mentioned physical cue used to categorize classmates (mentioned by 30 subjects). Individuals appear in the approach category because they are "clean cut" or "well groomed"; their hair is neatly trimmed, moderate in length (for men) and styled, orderly/combed and clean, and natural in color. For men that includes being clean shaven or having well groomed facial hair (mentioned by 15 subjects). On the other hand, classmates can be placed in the avoid category because their hair deviates too far from the "clean cut" look. That is, their hair is too long (for men), untrimmed, dirty, messy or "shaggy," colored/bleached, or styled in a way that is too different from the norm (e.g., spiked or highlighted for men). Hair appears to be most directly associated with conscientiousness (professional), agreeableness (cooperative, conforming, and approachable), and the extent to which one values self (appearance).

Tools/supplies attributes. Classmates to approach during team formation tend to have in their possession the tools and supplies relevant to class such as a writing instrument, paper, planner, textbook, and laptop computer. Having the needed tools and supplies is associated with conscientiousness, and being organized, hardworking, and reliable. However, just having supplies is not quite enough in that certain supplies also need to be orderly. Course materials that are neatly labeled, color coded, and highlighted, and papers or a backpack that is orderly are also associated with conscientiousness in that the individual is thought to be organized.

Body art attributes. Fifteen subjects who referenced body art did so when explaining classmates they would tend to avoid. The basic issue is that there is a point at which piercings and tattoos are too many, too prominent (e.g., nose, eyebrow, or lip piercings; stretched ears; 
tattoos on the neck or hands), or too bold/strong in meaning or symbolism. Individuals with too many, prominent, or bold body art are believed to be low in agreeableness; they are deemed rebellious, nonconforming, and unwelcoming.

Physique type. Being in good physical shape is generally deemed a positive trait and appears to be associated with positive personality characteristics and values. However, men who are too physically fit tend to be in the avoid category. According to subjects in this study, men who are "very muscular" or "buff" are thought to place too much value on their physique and spend too much time exercising. Thus, they will not be a committed team member who can be relied on do their fair share or do it well.

Age. Age, which was mentioned by 13 subjects, seems to have an inverted U-shaped relationship with personality traits and values. Classmates who are "too young," about 20-21 years old and younger, as well as those who are "too old," about 40-45 and older, seem to be associated with more negative personality traits and values than those who are "middle-aged." However, associations with age were dispersed across the personality dimensions and values. As such, there were not the dominant associations found with other cues. One association that was mentioned is that those who are "too young" or "too old" are thought, by some, to place high value on non-educational aspects of their life. Those who are "too young" just don't value their education as much as those who are "middle-aged," and those who are "too old" have families that may take too much of their time.

Sex. One's sex is the final physical cue that warrants inclusion in the consensus map. The cue was mentioned by 12 subjects ( 7 men and 5 women), 8 of whom ( 6 men and 2 women) explained their preference for working with women, and 4 of whom ( 1 man and 3 women) explained their preference for working with men. As shown in Table A.2, subjects inferred the 
sexes to differ on the conscientiousness and agreeableness dimensions of personality. For example, one subject (a man) explained the following reasoning chain while discussing images in his approach category: woman $\rightarrow$ not a procrastinator, comes to class prepared, went over material, timely with assignments (conscientiousness), cooperative (agreeableness), knowledgeable, good writer (intellect), $\rightarrow$ easier to work with, task assigned will be completed, not fight back (ability—team skills), good ideas (ability—knowledge/cognitive ability). On the other hand, a woman provided the following while explaining an image in her approach category: men $\rightarrow$ less argumentative than women and will go with flow (agreeableness) $\rightarrow$ good team members, good workers, do fair share, willingness to pursue ideas of others (ability - team skills).

(Not)smiling. For subjects in this study, smiling is the most commonly used behavioral cue used to categorize classmates ( 27 subjects). As one might expect, those who are observed smiling tend to be approached and those who do not smile tend to be avoided. Smiling is associated with extroversion - being friendly, outgoing, and positive, and it is associated with agreeableness — - being cooperative and welcoming.

Engaging in (ir)relevant classroom behaviors. The second most commonly mentioned behavioral cue ( 25 subjects) deals with what one is observed doing during class. In general, others are placed in the approach category when they are observed engaging in behaviors that are relevant to the class. Classmates who listen to lecture, take notes, use a highlighter, write in a planner, attend class, and are present throughout class tend to be approached, and those who do something else such as text, surf the Internet on a computer, doodle, sleep, miss class, and arrive late or leave early tend to be avoided. These classroom behaviors are associated with conscientiousness in that if others are observed doing what they are supposed to do in class are 
thought to be hardworking, organized, focused, and serious. The behaviors are also linked to beliefs about the extent to which one places high value on education.

(Not)socializing before class. This behavioral cue simply deals with whether or not someone socially interacts with classmates before class. Those who do tend to be placed in the approach category and those who do not tend to be placed in the avoid category. If one is observed socializing before class they tend to be thought of as high in agreeableness (approachable and welcoming). However, there was some evidence that the category in which one is placed depends on what he or she is socializing about. That is, others who are overheard talking about their social life—especially parties, bars, drinking, men/women, and fraternities/sororities - tended to appear in the avoid category. Talking about these topics is associated with placing high value on something other than one's education.

(Not)participating during class. This cue deals with whether a classmate actively participates in class, or is observed raising one's hand, asking or responding to questions, and commenting in a thoughtful way. Those in the avoid category remain quiet or they overdo their participation and, as one subject stated, "steal the spotlight." As with other social behaviors, participating in class appears to be associated with extroversion (confident and outgoing).

\section{Discussion}

\section{Implications for Research}

Pedagogical strategies are stimuli placed in students' environment to influence their cognition, affect, and behavior (Thorndike, 1906). The design of strategies such as team assignments and a complete understanding of their consequences for students should include an analysis of all three elements and the relationships that exist among them. While the rationale for using team assignments is that benefits or positive consequences accrue to students, this study highlights 
how self-selecting team members can result in several unintended negative consequences for at least some students.

First, some students in the context of this study respond to the problem of too little information during team formation by using a variety of social cues to cognitively categorize their classmates into at least two broad categories. One category appears to be comprised of those who fit, in appearance and behavior, a business school norm. The category was referred to by subjects as those who are "the norm," "normal," "normalized," "every day," "typical," "regular," "average Joe," or "all American." Prototypic features of the category consist of B-school casual clothes, well-groomed hair, "middle-age," moderately good physical shape, little or an absence of visible body art, and having in one's possession during class the relevant tools and supplies needed for class. Prototypical behaviors consist of those that are social—smiling, interacting with classmates before class, and participating during class, and nonsocial—engaging in relevant classroom behaviors.

On the other hand, some classmates are excluded from the category because they are too atypical, or they deviate too far from the B-school norm on one or more social cues. While the magnitude of the deviation necessary surely differs among students, there clearly are social cues for which a deviation is significant enough to cognitively separate some classmates from those who are in the B-school norm category. This categorization during team formation may be an activity performed by a large number of the undergraduate students in the business school at which this study took place. Recall that $100 \%$ of the subjects in this study reported having used social cues to some extent to make decisions about who to approach and who to avoid during team formation (shown in Figure 1). 
The second consequence of the self-selection process is also cognitive in that at least some students in the context of this study engage in stereotyping which is the process of making inferences about classmates based on the social category in which they are placed. (Schneider, 2004). While subjects were asked to represent via images those they would approach or avoid, the findings indicate that students infer those in the B-school norm category to possess a range of positive personality traits and values. And, even though subjects seldom used the label trustworthy, all 38 of them frequently spoke about others' ability, benevolence, and integrity, and the potential consequences of being in a team with others who are inferred to be high on one or more of the dimensions of trustworthiness.

Not only are classmates in the "other" category inferred to be relatively low in trustworthiness, they are also inferred to possess a wide range of negative personality traits, place too little value on education, place too little or too much value on self, and hinder one's ability to achieve a desired grade and contribute a fair share in doing so. And, perhaps most importantly, classmates in this category are associated with a number of negative emotional consequences which may be the underlying reason for avoiding them in the first place. In other words, the perceived threat of anxiety, anger, sadness, stress, annoyance, frustration, insecurity, and fear appears to be a main antecedent to avoiding some classmates. These negative emotions were in stark contrast to the positive emotions such as confidence and relief that were consistently associated with classmates in the B-school norm category. While this study features a reasoning chain and cognitive associations that include emotions, the positive or negative affective responses one actually experiences towards a social category of people or individuals from that category is prejudice (Schneider, 2004). 
The third unintended consequence of self-selection is behavioral in that students tend to approach those in the B-school norm category and avoid others who deviate too far from the norm on one or more social cues. Students' behaving differently towards their classmates due to the cognitive category in which they are placed, rather than on individual merit, is discrimination (Schneider, 2004). Since all subjects reported using social cues to decide who to approach or avoid during team formation, all subjects reported engaging in discriminatory behavior and 13 out of 38 reported doing so every time they have self-selected team members.

For some students their acts of discrimination appear to be the blatant, straight line type in that all members of certain groups are consciously avoided (Schneider, 2004). As was the case with one participant who explained that during the self-selection process he avoids all classmates he observes reading a non-English book because they are inferred to be English as Second Language (ESL) students. The subject explained that he avoids ESL students because they are "not as creative [and] are unable to understand course content as well as American students." As such, an ESL student would likely "produce low quality work" which would create "more work [and] a lot of stress for me." For other students their discrimination is more subtle and less conscious. Regardless of how conscious or subtle the discrimination, some groups of students appear to be routinely discriminated against by at least some of their classmates. Take, for example, students who actually are introverts. They would be less likely than extroverts to exhibit social cues such as interacting with classmates before class and actively participating during class (two behaviors that were mentioned by about one-half of the subjects in this study). In effect, introverts tend to be cognitively excluded from the B-school norm category because they are inferred to be low in communicativeness - an attribute of an ineffective team memberand weak in presentation skills. In turn, they tend to be associated with a poor grade on the final 
presentation and negative emotions that stem from that grade. This study indicates that students who are introverts are routinely and consciously targets of discrimination during the process of self-selecting team members. For example, one subject explained how he inferred that a student who "sits in the back corner away from others," is "quiet, not as outgoing," "has poor communication skills," "is not as willing to share ideas," "is not as willing to ask for help or clarification," and "might do his part [of the project] wrong," which will have a "negative effect on my grade," which makes me "anxious."

Several other personal factors appear to give rise to discrimination during the self-selection process. For example, in the context of this study, nontraditional students appear to be discriminated against because of their age. One of the most pointed illustrations arose when a subject explained that he avoids "older" people because they "lack academic skills," have "poor technology abilities," and "writing may be rusty," which would "hinder the group" so "I" would have to do "more babysitting," "monitor her work," which would cause "fear and uncertainty." Some students are targets of discrimination because of their physique or they "look like" student athletes. One subject explained that those who appear "buff" "spend a lot of time working out" so the team "project would not be high on his list of priorities," and "I would have to pick up slack, review his work," which would cause "stress." And, students who do not look or behave like the B-school norm due to lifestyle, socio-economic status, social milieu and a host of other personal factors are likely targets of discrimination during the self-selection process.

Fourth, self-selection diminishes the value of team assignment experiences when students avoid opportunities to learn about, and how to work with, others who are different. When students approach and form a team with others who were cognitively placed in a B-school norm category, they essentially form a team with classmates who are inferred to be similar to each other. At the 
same time, when students avoid classmates who were excluded from the B-school norm category, they avoid forming teams with classmates who are inferred to be different. When people socially categorize others and make inferences about them based on the category in which they are placed, some of the inferences will be correct (Schneider, 2004). That is, some of the people in a cognitive category really will be similar in some ways, and some people in a category really will be different from people in another category. As such, selecting team members based on the social category in which they are placed is an attempt to defeat one of the main intended benefits of team assignments which is to create an experience through which students learn about, and learn to work with, a diversity of people.

Not once during this study did a subject relate images in their approach category to learning about, or learning to work with, classmates who are different. There were a few instances of subjects placing images of the opposite sex or different race in their approach category, but the social cues followed the reasoning chain in Figure 2 and were associated with equity, higher performance, or positive emotional consequences. For example, a woman explained her preference for working with men because they 'interpret things different from a female and it's good to have that contrast in a group" because the "contrast" or different ideas lead to a better product and higher grade. In addition, three subjects mentioned a preference for working with Asians because they are inferred to be "studious," "serious about school," and "good with numbers" so while working on a team project they "will do really good work" and a lot of it which will also enhance performance. Race was mentioned by five subjects as they expressed their desire to work with others who are similar (which also means they prefer not working with classmates who are of a different race). As an example, an Asian American woman included multiple images of Asians in her approach category and explained that, since they were of the 
same race, she and those in the images would "get along better." The subject also explained that Asians "take care of their own" so the individuals in the images would "take care of me" which the subject associated with excitement. And, a Latino subject (born in Mexico) explained his desire to work with Latinos because they are similar in culture, first language, and values so they would likely become friends which was associated with happiness and security. Fifth, while the process of self-selecting team members may add value for some students by inducing fewer or less intense negative consequences and more frequent or intense positive consequences, the process likely induces very real negative consequences for those who are socially categorized as those to avoid. Those who are placed in the avoid category are socially marginalized and likely have a difficult time forming social networks. In addition, they likely experience a range of negative emotional consequences that, in turn, can lead to other unintended consequences. Such consequences were recently shared by a Korean female (not part of this study) who explained that when she was an international student in an MBA program at a university in the US, she nearly dropped out of school due to the emotional toll of consistently being the last student selected for team assignments. This individual who was, evidently, socially categorized by her classmates as one to avoid was very likely a high-value team member. After all, this individual earned her MBA, then her $\mathrm{PhD}$, and then became a tenure track professor. Finally, the aforementioned unintended consequences likely occur during all team formation processes in which students are given decision making authority in whole or part. For example, when students list others with whom they do and do not want to work (Matta et al., 2010) the lists likely result, at least in part, from students' social categorization and stereotyping. When students gather information from and about classmates before forming teams (Butterfield \& Pendegraft, 1996; Mello, 1993), they likely socially categorize classmates and decide who to 
approach and gather information from based on the category in which they are placed. And, when students engage in constrained self-selection (Bacon et al., 2001) they likely engage in stereotyping and discrimination. That is, when students are told to meet a quota from a certain group of students (e.g., each team must have at least one man and one woman), the constraint only prevents the use of the social cue defined by the constraint (e.g., one's sex cannot be used to decide who will fill two seats on the team). However, students can still use other social cues to categorize members within the group (e.g., one can still use clothes to socially categorize women into subcategories). And, while the social cue is not available for the decisions defined by the constraint (e.g., one space on the team has to be taken by a man and one by a woman), students still have complete decision making authority for other spaces on the team.

\section{Implications for Practice}

Team assignments should be designed to bring about intended positive consequences and eliminate those that are unintended and negative. A primary benefit for students is the development of diversity consciousness. Buchar (2015) defines diversity as all of the ways in which people are different, and diversity consciousness as understanding, awareness, and skills in the area of diversity. Diversity skills are then the competencies that allow people to interact with others in a way that respects and values differences.

To bring about this intended positive consequence and eliminate the aforementioned unintended negative consequences, instructors need to assume full responsibility for making decisions about who works with whom and employ a decision-making process that leads to intra-team diversity. Doing so at least ensures that students will have the opportunity to work with, and learn about, others who are different. This study and others that report criteria used by students to judge classmates and self-select team members (Connerly \& Mael, 2001; Seethamraju \& Borman, 
2009; Neu, 2012), indicate that students do not self-select a diversity of team members to learn about others who are different. Instead, students tend to self-select classmates to achieve intrateam homogeneity on several personal attributes, and to achieve intra-team diversity on the skills, knowledge, and abilities needed to perform well on the assignment.

Instructors need to gather and use data from and about students to achieve intra-team diversity. The list of possible diversity-related attributes on which to gather data is long (Buchar 2015), and the process of gathering, organizing, and using data to make decisions can be cumbersome and time consuming. To relieve some of the burden, instructors can use TEAM-MAKER, available online at www.CATME.org. The tool collects information from and about students and assigns students to teams to achieve instructor-specified goals. A different program by a very similar name was developed some years earlier and presented in Bacon et al. (2001), but this alternative version is no longer being supported.

Simply assigning students to diverse teams does not ensure that students will interact with and learn about each other (Buchar, 2015; Neu, 2012). As such, if a team assignment is intended to develop students' diversity consciousness, then the team assignment experience should be designed to motivate such learning. One possibility is to start the team experience with a multicultural service sensitivity exercise developed by Rosenbaum, Moraru, and Labrecque (2014). Even though the exercise was designed to encourage "future service managers to understand how customers of different race, ethnicity, culture, language, religion, gender, sexual orientation, and physical abilities and disabilities may experience discrimination in service settings from employees and customers" (Rosenbaum et al., 2014, p. 8), the exercise could be adapted to help students recognize and understand the potential discrimination during team assignments and what students and the instructor can do to cease discriminatory behavior. Prior 
to launching a team assignment, two of the frameworks developed by Rosenbaum et al. (2014) could be used to help students identify the types of discriminatory behaviors that students might experience during team assignments, and possible solutions to eliminate discriminatory behaviors. In addition, the team assignment experience itself should include a component that requires individual students to actively engage in exercises to critically reflect on and develop their understanding, awareness, and skills in the area of diversity. And, students should be evaluated on the extent to which they do. For ideas on how to develop such experiences, instructors might turn to Buchar's (2015) Chapter 4 titled "Developing Diversity Consciousness." Here Buchar explains six areas of development and exercises that can be used to help students develop in each area.

\section{Limitations and Opportunities for Future Research}

As with any research this study is not without its limitations, some of which suggest

opportunities for future research. Specifically, all 38 subjects were selected from two sections of an upper division Marketing Research class taught at one business school. Gathering data from a more diverse sample of subjects, such as from different business schools, could extend the findings presented in this study. In addition, the sample was comprised of 13 women and 25 men. While the objectives of this study did not include understanding how men and women differ in the extent to which and the way in which social cues are used during self-selection, if differences do exist the results of this study would be biased towards men. Relatedly, the sample may have been biased towards students who themselves would tend to be cognitively placed in the B-school norm category. If that was the case, results of the study would also be biased towards those who could be similar in some ways. For example, the sample may have been biased towards extroverts or those who place especially high value on their academic 
performance (they were willing to participate for extra credit). Additional research could be directed at understanding the ways in which and the extent to which social categorization differs among different subgroups of students. Furthermore, this study focused on self-selection which involves granting students complete decision-making authority for who works with whom. Research on social categorization could also be directed at other types of team formation processes during which students have decision-making authority in whole are part. Those methods include giving students time to gather information from and about classmates before selecting teammates, asking students to list others with whom they do and do not want to work, or requiring that students self-select team members in a constrained way. Finally, this study does not provide the statistical generalizability to a larger population offered by a large-sample quantitative study. As such, there is a need to formally test the relationships shown in Figure 2. One very pressing issue is to investigate the effects on students who are routinely socially categorized as those to avoid during the team formation process. Those who are avoided likely experience negative cognitive, affective, and behavioral consequences that deserve to be understood. 


\section{Appendix}
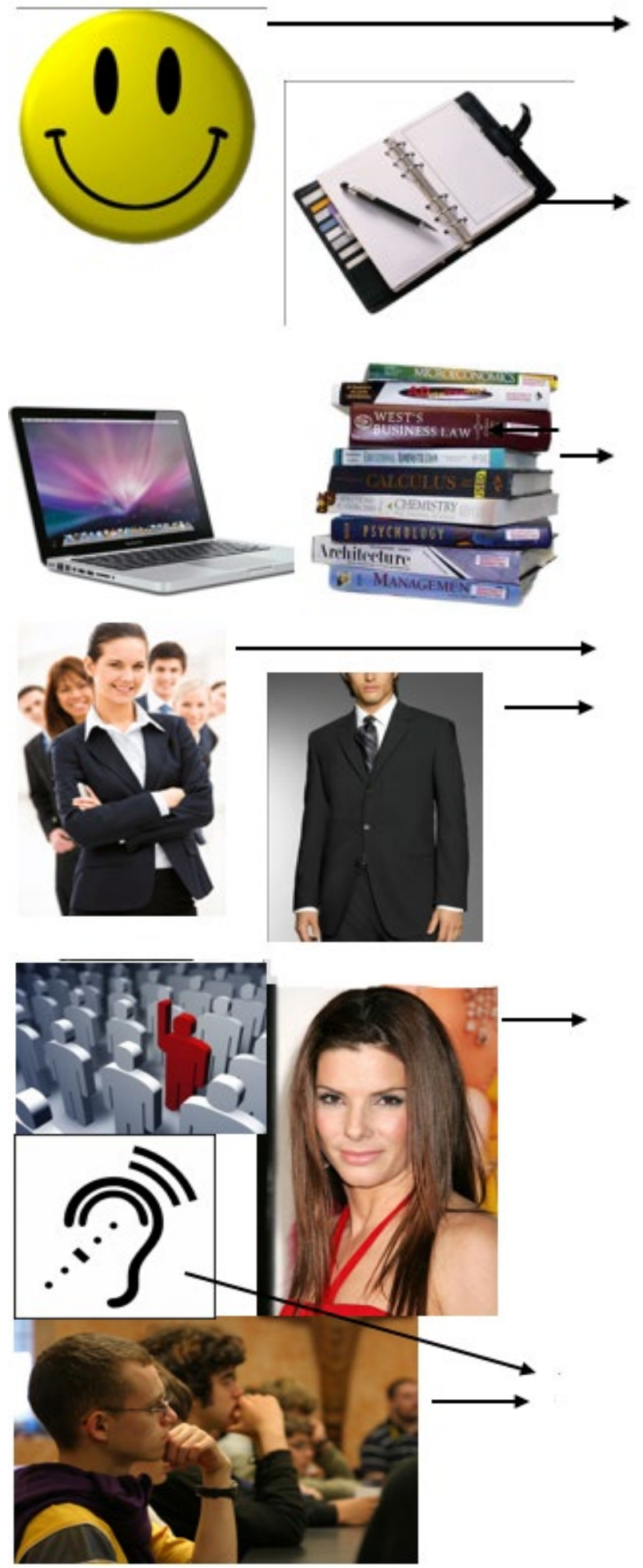

The subject explained that a classmate who smiles is a friendly, approachable person who is easy to work with, less argumentative, receptive to others' ideas, which leads to feelings of warmth, comfort, happiness, and confidence.

A student who is observed using a planner is thought to be organized, and an organized student would be a reliable team member who does his/her work on time and contributes quality work.

The subject explained that a student who brings to class the course textbook puts forth high effort toward learning, and would be a reliable team member who does his/her fare share. The image was associated with comfort, less stress, and confidence.

These images were used to explain that a classmate who wears business or business casual clothes is a selfconfident, organized, professional, multi-tasker (balance school and work). The individual is thought to have real experiences and knowhow that will apply to a team project which will, in turn, lead to better performance on the project and feeling happy, confident, and not frustrated.

The subject explained that a female classmate with natural colored hair and little but natural looking make-up places high priority on school rather than her personal appearance. In turn, she would be a reliable team member who focuses on work rather than self and who completes her tasks on time. The image was associated with comfort.

These images were used to explain that students who are attentive during class and listen to the professor know or understand course content. In turn, they will be able to apply course content to the team project which will lead to a better grade and feelings of happiness and relief.

\section{Figure A.1. One Subject's Images Representing Classmates to Approach}




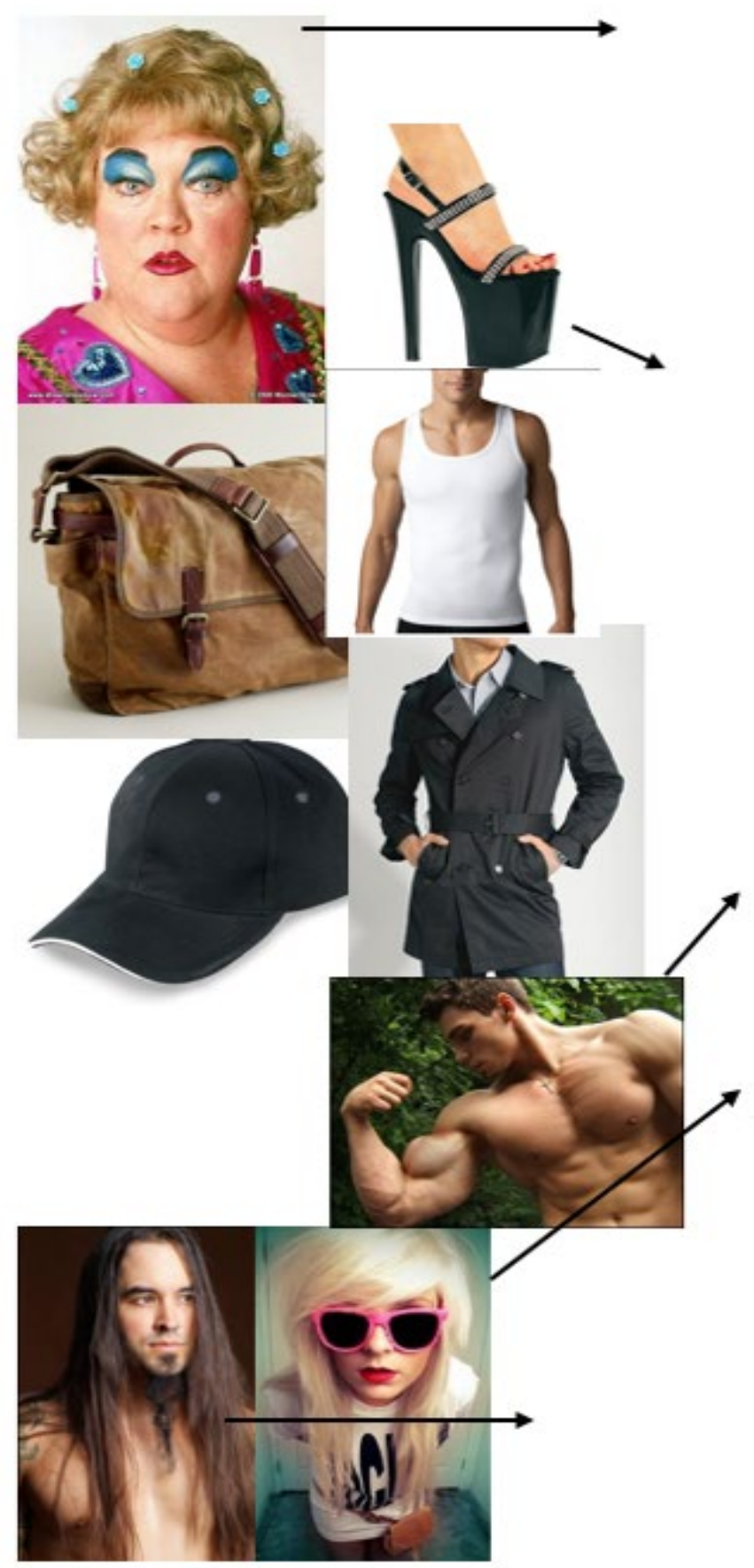

The subject used this image to explain that women who wear too much makeup have the wrong priorities - they value bettering themselves rather than team members, and fashion rather than education. In addition, those who wear too much make-up do not have a professional job, are not serious, and have low confidence. In turn, they would produce low quality work that would not be on time, which would lead to confrontation, a fight about priorities, and stress.

The subject explained that a student who wears highheeled shoes is very fashion oriented, has the wrong priorities, and would likely be late with work on a group project. The image was associated with feeling uneasy, uncomfortable, and stressed.

This image was used to explain that a male student who is very muscular focusses too much on himself. On a group project he would try to take on a limited amount of work, and his work would likely be untimely and low quality. The image was also associated with feeling uncomfortable and on edge.

The subject explained that platinum blond hair and excessive makeup indicate that the individual is unapproachable, standoffish, can't be taken seriously, and has non-school priorities like partying and hanging out with friends. In turn, the student would likely miss meetings or not be available on weekends, would not be a team player, would provide subpar quality work that would not be on time. The image was associated with anger and stress.

Here the subject explained that a student with dirty hair cares too little about himself. In turn, he would likely care too little for the group project and produce low quality work. The image was associated with feeling uneasy and uncomfortable.

\section{Figure A.2. One Subject's Images Representing Classmates to Avoid}




\section{Table A.1. Interferences and Number of Subjects Who Mentioned Them}

\begin{tabular}{|c|c|c|c|c|c|}
\hline Personality & 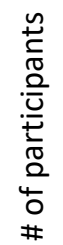 & Trustworthiness & 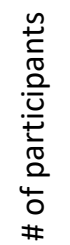 & Goals & 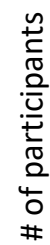 \\
\hline Conscientiousness & 36 & Ability & 38 & (In)equity & 38 \\
\hline Hardworking & 20 & Reliability (team skill) & 33 & Performance outcomes & 17 \\
\hline Organized & 19 & Communicativeness (team skill) & 28 & Negative emotions & 35 \\
\hline Focused/dedicated & 16 & Cooperativeness (team skill) & 25 & Anxiety/uncertainty & 19 \\
\hline Reliable & 13 & Commitment (team skill) & 24 & Anger & 17 \\
\hline Professional & 13 & Flexibility (team skill) & 12 & Sadness/unhappiness & 14 \\
\hline Timely & 10 & Work skills & 19 & Stress & 14 \\
\hline Responsible & 7 & Knowledge/cognitive abilities & 18 & Annoyed & 10 \\
\hline Disciplined & 7 & Benevolence & 9 & Frustration & 9 \\
\hline Good time manager & 6 & Integrity & 7 & Insecurity & 7 \\
\hline Attention to detail & 3 & & & Fear/scared & 6 \\
\hline Proactive & 3 & & & Positive emotions & 24 \\
\hline Agreeableness & 31 & & & Confidence & 16 \\
\hline Welcoming/approachable & 21 & & & Relief & 15 \\
\hline Agreeable/cooperative & 20 & & & Happiness & 9 \\
\hline Easy-going & 11 & & & Excitement & 8 \\
\hline Helpful & 10 & & & Security & 5 \\
\hline
\end{tabular}

\begin{tabular}{l|c|}
\multicolumn{1}{l|}{ Unselfish } & 2 \\
\hline Extraversion & 28 \\
\hline Outgoing & 18 \\
\hline Friendly & 14 \\
\hline Confident & 9 \\
\hline Fun & 6 \\
\hline Positive/optimistic & 6 \\
\hline Enthusiastic & 2 \\
\hline Openness/intellect & 26 \\
\hline Intelligent & 19 \\
\hline Open-minded & 8 \\
\hline Creative & 8 \\
\hline Values & \\
\hline Education/non education & 31 \\
\hline Self: appearance/health & 24 \\
\hline
\end{tabular}


Table A.2. Social Cues, Concept Pairs, and Number of Subjects Who Mentioned Them

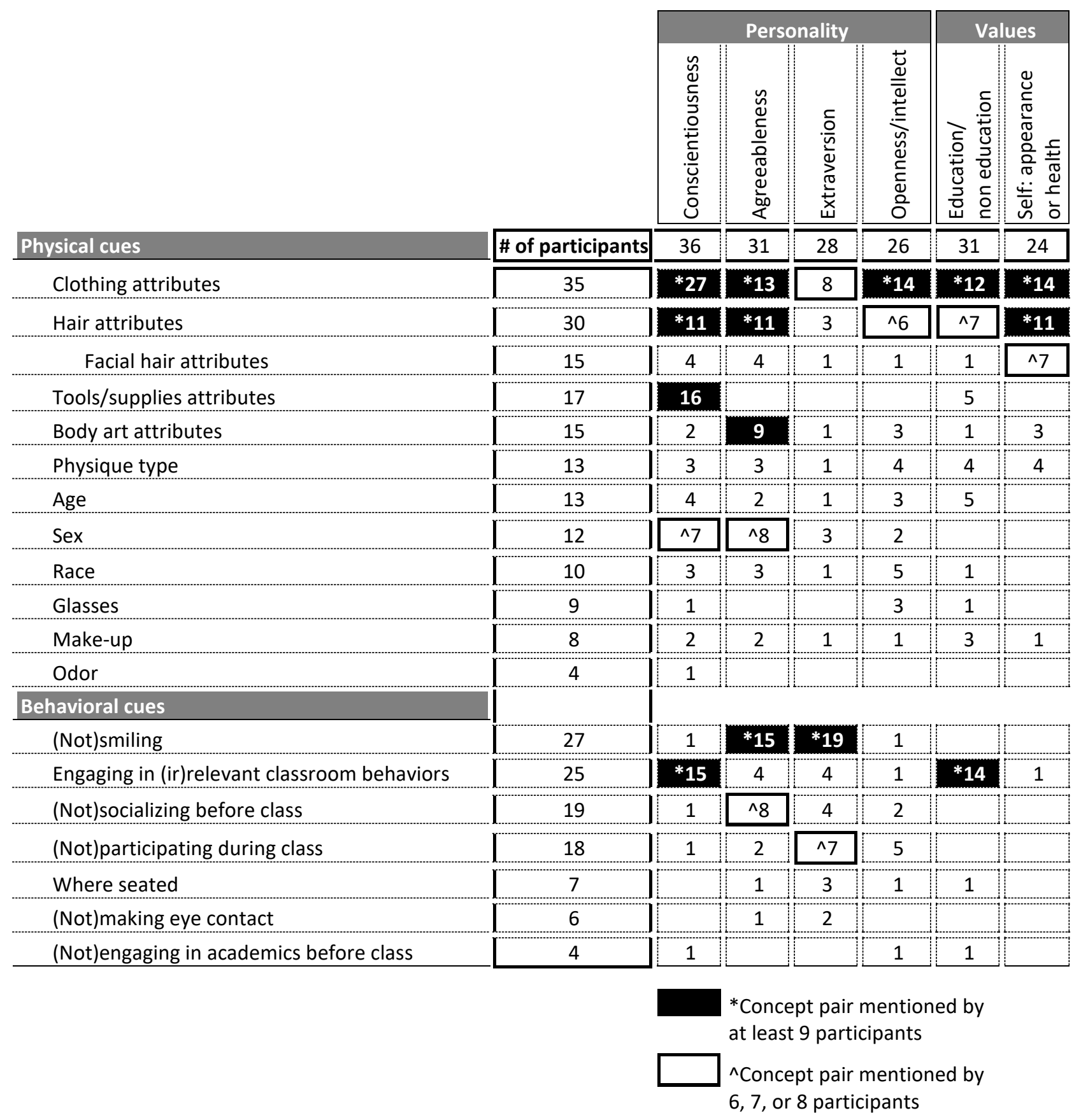




\section{References}

Bacon, D. R., Stewart, K. A., \& Stewart-Belle, S. (1998). Exploring predictors of student team project performance. Journal of Marketing Education, 20(1) 63-71.

Bacon, D. R., Stewart, K. A., \& Anderson, E. S. (2001). Methods of assigning players to teams: A review and novel approach. Simulation \& Gaming, 32(1), 6-17.

Batra, M. M., Walvoord, B. E., \& Krishnan, L. S. (1997). Effective pedagogy for student-team projects. Journal of Marketing Education, 19(1), 26-42.

Beheshtian-Ardekani, M., \& Mahmood, M. A. (1986). Development and validation of a tool for assigning students to groups for class projects. Decision Sciences, 17, 92-113.

Blowers, P. (2003). Using student skill self-assessment to get balanced groups for group projects. College Teaching, 50(3), 106-110.

Buchar R. D. (2015). Diversity consciousness: Opening our minds to people, cultures, and opportunities. New York, NY: Pearson.

Butterfield, J., \& Pendegraft, N. (1996). Gaming techniques to improve the team-formation process. Team Performance Management: An International Journal, 2(4), 11-20.

Chapman, K., Meuter, M., Toy, D., \& Wright, L. (2006). Can't we pick our own groups? The influence of group selection method on group dynamics and outcomes. Journal of Management Education, 30(4), 557-569.

Crosby, F., Bromley, S., \& Saxe, L. (1980). Recent unobtrusive studies of black and white discrimination and prejudice: A literature review. Psychological Bulletin, 87(3), 546-563.

Driscell, J. E., Goodwin, G. F., Salas, E., \& O'Shea, P. G. (2006). What makes a good team player? Personality and team effectiveness. Group Dynamics: Theory, Research, and Practice, 10(4), 249-271. 
Connerley, M. L., \& Mael, F. A. (2001). The importance and invasiveness of student team selection criteria. Journal of Management Education, 25(5), 471-494.

Deeter-Schmelz, D. R., Kennedy, K. N., \& Ramsey, R. P. (2002). Enriching our understanding of student team effectiveness. Journal of Marketing Education, 24(2), 114-124.

Dommeyer, C. J. (2007). Using the diary method to deal with social loafers on the group project: Its effects on peer evaluations, group behavior, and attitudes. Journal of Marketing Education, 29(2), 175-188.

Eisenhardt, K. M. (1989). Building theories from case study research. Academy of Management Review, 14(4), 532-550.

Feichtner, S. B., \& Davis, E. A., (1985). Why some groups fail: A survey of students’ experiences with learning groups. Journal of Management Education, 9(4), 77-88.

Glaser, B. G., \& Strauss, A. L. (1967), The discovery of grounded theory: strategies for qualitative research, Hawthorne, NY: Aldine Publishing.

Gosenpud, J. (1989). The prediction of simulation performance as it is affected by time. Simulation \& Gaming: An International Journal, 20(3), 319-350.

Hansen, R. S. (2006). Benefits and problems with student teams: Suggestions for improving team projects. Journal of Education for Business, 82(1), 11-19.

Huxham, M., \& Land, R. (2000). Assigning students in group work projects: Can we do better than random? Innovation in Education and Training International, 37(1), 17-22.

Jalajas, D. S., \& Sutton, R. I. (1984-1985). Feuds in student groups, coping with whiners, martyrs, saboteurs, bullies, and deadbeats. Organizational Behavior Teaching Review, $9(4), 217-227$. 
Jaworski, B. J., MacInnis, D. J., and Kohli, A. K. (2002). Generating competitive intelligence in organizations. Journal of Market-Focused Management, 5(4), 279-307.

John, O. P., and Srivastava, S. (1999). The big five trait taxonomy: History, measurement, and theoretical perspectives. In L. A. Pervin and O. P. John (Eds.), Handbook of personality: Theory and research (pp. 102-138). New York, NY: Guildford.

Mahenthiran, S., \& Rouse, P. J. (2000). The impact of group selection on student performance and satisfaction. International Journal of Educational Management, 14(6), 255-264.

Matta, V., Luce, T., \& Ciavarro, G. (2010). Exploring impact of self-selected student teams and academic potential satisfaction. Proceedings of the Information Systems Educators Conference, 27(1304), 1-10.

Mayer, R. C., Davis, J. H., \& Schoorman, D. F. (1995). An integrative model of organizational trust. Academy of Management Review, 20, 709-734.

McCorkle, D. E., Reardon, J., Alexander, J. F., Kling, N. D., Harris, R. C., \& Iyer, R. V. (1999). Undergraduate marketing students, group projects, and teamwork: The good, the bad, and the ugly?. Journal of Marketing Education, 21(2), 106-117.

Medin, D. L. (1988). Social categorization: Structures, process, and purposes. In T. K, Srull \& R. S. Wyer, Jr. (Eds.), Advances in social cognition (Vol. 1, pp. 119-126). Hillsdale, NJ: Erlbaum.

Mello, J. A. (1993). Improving individual member accountability in small work group settings. Journal of Management Education, 17(2), 253-259.

Muller, T. E. (1989). Assigning students to groups for class projects: An exploratory test of two methods. Decisions Sciences Journal, 4, 623-634. 
Loughry, M. L., Ohland, M. W., \& Moore, D. D. (2007). Development of a theory-based assessment of team member effectiveness. Educational and Psychological Measurement, $67(3), 505-524$

Neu, W. A. (2012). Unintended cognitive, affective, and behavioral consequences of group graded assignments. Journal of Marketing Education, 34(1) 67-81.

Patton, M. Q. (2002). Qualitative research and evaluation methods. Thousand Oaks, CA: Sage Publications.

Potosky, D., \& Duck, J. (2007). Forming teams for classroom projects. Developments in Business Simulation and Experiential Learning, 34, 144-148.

Rosenbaum, M. S., Moraru, I., Labrecque, L. I. (2014). A multicultural service sensitivity exercise for marketing students. Journal of Marketing Education, 35(1), 5-17.

Schneider, D. J. (2004). The psychology of stereotyping. New York, NY: The Guilford Press.

Scott, T. J., Bisland, R. B., Tichenor, L. H., \& Cross, J. H. (1994), Team dynamics in student programming projects. Proceedings of the twenty-fifth SIGCSE symposium on Computer science education, 26(1), 111-115.

Seethamraju, R., \& Borman, M. (2009). Influence of group formation choices on academic performance. Assessment \& Evaluation in Higher Education, 34(1), 31-40.

Stephan, W. G., \& Stephan, C. W., (1993). Cognition and affect in stereotyping: Parallel interactive networks. In D. M. Mackie \& D. L. Hamilton (Eds.), Affect, cognition, and stereotyping: Interactive process in group processes (pp. 111-136). San Diego, CA: Academic Press.

Strauss, A. L., \& Corbin, J. M. (1998). Basics of qualitative research: Techniques and procedures for developing grounded theory. Thousand Oaks, CA: Sage Publications. 
Taylor, S. E. (1981). A categorizing approach to stereotyping. In D. L. Hamilton (Ed.), Cognitive processes in stereotyping and intergroup behavior (pp. 83-114). Hillsdale, NJ: Erlbaum.

Thorndike, E. L. (1906). Introduction. In The principles of teaching: Based on psychology (pp. 111). New York, NY: A. G. Seiler.

Williams, D. L., Beard, J. D., \& Rymer, J. (1991). Team projects: Achieving their full potential. Journal of Marketing Education, 13(1), 45-53.

Wood, C. M. (2003). The effects of creating psychological ownership among students in group projects, Journal of Marketing Education, 25(3), 241-249.

Zaltman, G., \& Coulter, R. H. (1995). Seeing the voice of the customer: Metaphor-based advertising research. Journal of Advertising Research, 35(4), 35-51. 